\title{
Risk factors for Lassa fever infection among survivors at the Federal Medical Center, Owo, Ondo State, Nigeria
}

\author{
Olayinka Stephen Ilesanmi ${ }^{1,2}$ (D) , Oluwatosin Temitope Owoeye-Lawal ${ }^{3}$ (D) Adewale Johnson Aro $^{3}$ (D), \\ Aanuoluwapo Adeyimika Afolabi1(iD), Adesola Olawumi Kareem³ (iD, Chukwuyem Abejegah ${ }^{3}$ (i) and Oladele Oluwafemi Ayodeji ${ }^{3}$ (D) \\ 1. Department of Community Medicine, College of Medicine, University of Ibadan, Ibadan, Oyo State, Nigeria; \\ 2. Department of Community Medicine, University College Hospital, Ibadan, Oyo State, Nigeria; 3. Department of \\ Community Health, Federal Medical Centre, Owo, Ondo State, Nigeria. \\ Corresponding author: Olayinka Stephen Ilesanmi, e-mail: ileolasteve@yahoo.co.uk \\ Co-authors: OTO: tosinowoeyelawal@gmail.com, AJA: aroadewale@gmail.com, AAA: afoannade@gmail.com, \\ AOK: drsolad@yahoo.com,CA: cabejegah2007@gmail.com,OOA: femiayodeji@yahoo.com
}

Received: 15-10-2020, Accepted: 05-04-2021, Published online: 23-06-2021

doi: www.doi.org/10.14202/IJOH.2021.128-134 How to cite this article: Ilesanmi OS, Owoeye-Lawal OT, Aro AJ, Afolabi AA, Kareem AO, Abejegah C, Ayodeji OO (2021) Risk factors for Lassa fever infection among survivors at the Federal Medical Center, Owo, Ondo State, Nigeria, Int. J. One Health, 7(1): 128-134.

\begin{abstract}
Background and Aim: There is insufficient information about the successfully managed Lassa fever (LF) patients in Nigeria. This study aimed to utilize the One Health approach to identify the risk factors for LF infection among LF patients who were managed and on follow-up at the Federal Medical Center, Owo, Ondo State, Nigeria.

Materials and Methods: A cross-sectional study was done on 101 LF survivors who were managed and on follow-up at the Federal Medical Center. The data were collected using a semi-structured interviewer-administered questionnaire. The respondents were assessed for symptoms and factors that might have predisposed them to LF, and the data were analyzed with SPSS version 23 (IBM Corp., NY, USA). Those who had more than 3 identifiable risks were categorized as high risk. Descriptive statistics were done, and the association between sociodemographic characteristics and high risk was explored using Chi-square test.
\end{abstract}

Results: The median age of the respondents was 33 years (8-85 years); 62 (61.4\%) were male, and 93 (92.1\%) have heard of LF before diagnosis. The perceived cause of LF infection among the respondents included the consumption of food contaminated by rats' feces among $57(56.4 \%)$ persons, while $16(15.8)$ attributed their infection to contact with LF-infected persons. Among the respondents with primary education and below, $5(29.4 \%)$ were at higher risk for LF infection compared to $7(8.3 \%)$ with secondary education and above $(\mathrm{p}=0.014)$.

Conclusion: The mass media and other sources of information should be well-harnessed in the communication of risks and preventive practices for LF. Public information campaigns should be organized to discourage bush burning in affected communities.

Keywords: health education, Lassa fever infection, Lassa fever prevention, Lassa fever, mass media, Nigeria, risk factors for Lassa fever.

\section{Introduction}

Lassa fever (LF) is an acute viral zoonotic illness caused by the Lassa virus (an arenavirus); it is characterized by fever, muscle ache, sore throat, nausea, vomiting, and chest and abdominal pain [1]. Approximately 29 imported LF cases were documented worldwide, and one-third of which was fatal [2-6]. LF is endemic in West African countries (Nigeria, Sierra Leone, Guinea, and Liberia). In Cote d'Ivoire, Ghana, Togo, and Benin, the seroprevalence was found to be lower, but isolated cases showed evidence of viral circulation [3-5]. Across this subregion, LF affects about 3-5 million individuals yearly, causing about 5000-10,000 deaths [7,8].

Copyright: Ilesanmi, et al. This article is an open access article distributed under the terms of the Creative Commons Attribution 4.0 International License (http://creativecommons.org/licenses/ by/4.0/), which permits unrestricted use, distribution, and reproduction in any medium, provided you give appropriate credit to the original author(s) and the source, provide a link to the Creative Commons license, and indicate if changes were made. The Creative Commons Public Domain Dedication waiver (http:// creativecommons.org/ publicdomain/zero/1.0/) applies to the data made available in this article, unless otherwise stated.
LF was first described in the 1950s in Sierra Leone; it was identified as a viral infection in 1969, but it was not named until the death of two missionaries in Lassa village, Nigeria, West Africa [9]. LF is caused by an enveloped, single-stranded, bisegmented RNA virus that belongs to Arenaviridae family and is a disseminated systemic primary viral infection [9]. The natural hosts of the virus are multimammate rats (Mastomys natalensis) that breed frequently and are widely distributed throughout the West, Central, and East Africa [9]. These multimammate rats are probably the most common rodent in tropical Africa that are more often found in rural areas and dwellings than in the surrounding countryside [5].

The last decade has seen the emergence and re-emergence of viral hemorrhagic fevers (VHFs) in Nigeria and West African subregion. Not unexpectedly, most of the imported LF cases originated from Nigeria, Sierra Leone, Liberia, or Guinea [10]. However, to date, at least three imported cases have been identified outside of these four countries, suggesting the wider distribution of LF virus and challenging 
the current dogma of LF endemicity [3]. VHFs pose a great challenge to public health globally due to the high infectivity, morbidity, and mortality associated with this group of diseases.

The seasonal outbreaks of LF have continued in Nigeria, with cases now being recorded in states that have not been affected in the past. From January 1 to July 29, 2020, a total of 5366 suspected cases were reported from 27 states, including the Federal Capital Territory (FCT) and Abuja. Of these, 1051 were confirmed positive, and 4315 were negatives. Since the onset of the 2020 outbreak, there have been 219 deaths of confirmed cases [10]. The case-fatality ratio in confirmed cases was $20.8 \%$. Twenty-seven (27) states (Ondo, Edo, Bauchi, Nasarawa, Ebonyi, Plateau, Taraba, Abia, Anambra, Adamawa, Gombe, Borno, Kaduna, Kano, Katsina, Benue, Rivers, Kogi, Enugu, Imo, Delta, Oyo, Kebbi, Sokoto, Ogun, Osun, and Lagos) and the FCT recorded at least one confirmed case across 129 local government areas, and Ondo State contributes the highest, making up the $34 \%$ of the total national figure [10].

The One Health approach has been implicated in LF transmission $[11,12]$. The One Health approach is composed of environmental, human, and animal factors. LF is a disease of animal origin. The rats found in the houses of infected people have been found to be seropositive for the virus about 10 times more than those in the control houses [12]. Viralantibodies are produced after a febrile illness in twice as much in people who eat rats relative to those who do not. The environmental transmission of LF could occur through contact with the droppings (feces or urine) of multimammate rats. Human transmission could also occur through contact with infected body fluids. This mode of transmission mostly occurs while caring for sick persons either by relatives or health care workers $[11,12]$.

To the best of our knowledge, there is insufficient information about the perceived risk factors for LF infection among successfully managed cases in Nigeria. The identification of these factors is needed to inform the uninfected persons about the risk factors of LF and prevent further LF outbreaks, particularly in LF endemic areas. This study aimed to utilize the One Health approach to identify the risk factors for LF infection among LF patients who were managed and on follow-up at the Federal Medical Center, Owo, Ondo State, Nigeria.

\section{Materials and Methods}

\section{Ethical approval and Informed consent}

Ethical approval was obtained from the ethical review committee of Federal Medical Centre, Owo, Ondo State (FMC/OW/380/VOL. LXVII/187). The consent was obtained from all respondents before the commencement of data collection.

\section{Study period and location}

The study was conducted from May to August 2019 at the Federal Medical Centre, Owo, located in Owo Local Government Area of Ondo State in Nigeria. The hospital, though a tertiary health institution, provides primary, secondary, and tertiary levels of health care to the people within its catchment areas; Ondo, Kogi, Edo, Ekiti, Osun, and neighboring states. The Infection Control Ward (ICW) started out as a response to managing LF in January 2017. The ICW became LF Infection Control and Research Centre (ICRC) after the unprecedented outbreak of LF disease in the first few months of 2018. A 34-bedded facility was provided on February 28, 2018, in this regard. The ICRC collaborates with other national and international organizations for research and management such as the Nigeria Centre for Disease Control, Alliance for International Medical Action, and African Centre of Excellence for Genomics of Infectious Diseases. The activities of the ICRC are controlled through an Emergency Operations Centre that was set up to serve as the command center for all activities during an outbreak. Aside from clinical management of cases, a follow-up clinic exists for discharged patients with an average number of 25 patients seen monthly.

\section{Study design}

A descriptive cross-sectional study was employed.

\section{Study participants}

The study participants were LF patients who were successfully managed, discharged, and on follow-up at the ICRC of the hospital. All consenting adults were included in the study. Consent was obtained from the parents of persons aged $<18$ years. All confirmed persons who died at the time of this study were excluded from the study.

\section{Sample size determination}

The minimum sample size was calculated using the Leslie and Kish formula for descriptive studies [13]:

$$
\mathrm{n}=\mathrm{z}^{2} \mathrm{p}(1-\mathrm{p}) / \mathrm{d}^{2}
$$

where, $\mathrm{n}$ is the minimum sample size needed

- $\mathrm{d}$ is the level of error that can be tolerated (0.05 chance of error)

- $\mathrm{p}$ is the proportion of households in an LF endemic community at risk of LF due to presence of rodents in their houses $(96.1 \%)^{22}$

- $\mathrm{z}$ is the standard normal deviate corresponding to $95 \%$ confidence level.

At $95 \%$ confidence level, $\mathrm{z}=1.96$

$\mathrm{n}=1.96^{2} \times 0.96(1-0.96) / 0.05^{2}$

$\mathrm{n}=3.8416 \times 0.96 \times 0.04 / 0.0025$

$\mathrm{n}=58.9$

The minimum sample size was rounded up to 65 by adding a non-response rate of $10 \%$. However, a total of 101 recovered persons were interviewed from May to August 2019.

\section{Data collection}

The data were collected by the resident doctors of the Department of Community Medicine, Federal 
Medical Center using a semi-structured interviewer-administered questionnaire. The respondents were assessed for their knowledge on LF, the symptoms and factors that may have predisposed them to contract LF, and the behavioral modifications after recovery to prevent its recurrence among them and their family members.

\section{Statistical analysis}

The data were analyzed with SPSS version 20.0. The descriptive results were presented using frequency tables and charts. The risk scores were computed using six questions, with " +1 " assigned for presence and " 0 " assigned for absence. Only those who had cumulative risk scores $>3$ were categorized as high risk. The association between sociodemographic characteristics and risk factors was assessed using Chi-square test at 5\% significance level.

\section{Results}

A total of 101 respondents were interviewed among LF-infected persons visiting the Federal Medical Center. The median age of the respondents was 33 years, ranging from 8 to 85 years, with 42 people $(41.6 \%)$ with ages between 25 and 39 years. Among the respondents, $62(61.4 \%)$ were male, and $45(44.6 \%)$ had attained tertiary education. The other sociodemographic characteristics are shown in Table-1.

Among the respondents, 93 (92.1\%) have heard of LF before diagnosis. Fifty-seven $(56.4 \%)$

Table-1: Sociodemographic characteristics of Lassa fever confirmed persons, Federal Medical Centre, Owo.

\begin{tabular}{|c|c|c|}
\hline Variable $(n=101)$ & Frequency & $\%$ \\
\hline \multicolumn{3}{|l|}{ Age group (years) } \\
\hline$<25$ & 23 & 22.8 \\
\hline $25-39$ & 42 & 41.6 \\
\hline $40-59$ & 26 & 25.7 \\
\hline$\geq 60$ & 10 & 9.9 \\
\hline \multicolumn{3}{|l|}{ Sex } \\
\hline Male & 62 & 61.4 \\
\hline Female & 39 & 38.6 \\
\hline \multicolumn{3}{|l|}{ Religion } \\
\hline Christianity & 84 & 83.2 \\
\hline Islam & 17 & 16.8 \\
\hline \multicolumn{3}{|l|}{ Highest level of education } \\
\hline Primary and below & 17 & 16.8 \\
\hline Secondary & 39 & 38.6 \\
\hline Tertiary & 45 & 44.6 \\
\hline \multicolumn{3}{|l|}{ Ethnicity } \\
\hline Yoruba & 75 & 74.3 \\
\hline Ibo & 14 & 13.9 \\
\hline Hausa & 4 & 4.0 \\
\hline Others* & 8 & 7.9 \\
\hline \multicolumn{3}{|l|}{ Occupation } \\
\hline Artisan/trader & 42 & 41.6 \\
\hline Teacher/civil servant/health worker & 26 & 25.6 \\
\hline Student & 24 & 23.8 \\
\hline Unemployed/retirees & 9 & 8.9 \\
\hline \multicolumn{3}{|l|}{ Marital status } \\
\hline Single & 32 & 31.7 \\
\hline Married & 69 & 68.3 \\
\hline
\end{tabular}

International Journal of One Health, EISSN: 2455-8931 respondents perceived the consumption of food contaminated by rats' feces as the cause of their infection, while $16(15.8 \%)$ attributed their infection to contact with LF-infected persons. Sixteen persons (15.8\%) stated that LF was either due to unknown cause or the devil's attack, while $12(11.9 \%)$ mentioned that LF was caused by rat handling.

The main sources of information regarding LF were either through mass media $(55.9 \%)$ or friends (28\%). Six persons $(6.5 \%)$ were informed regarding LF by the hospital or school. The other sources of LF information are described in Figure-1.

The presence of fever that is unresponsive to antimalarial drugs and antibiotics was mainly reported in 97 (96\%) respondents, while 78 (77.2\%) experienced headache as a symptom of LF infection. Sixtytwo persons $(61.4 \%)$ presented with body weakness, while 49 persons $(47.5 \%)$ had cough following LF. The other symptoms of LF infection are shown in Figure-2.

The presence of bush around the house was stated as a risk factor for LF among 63 persons (62.4\%), while 59 (58.4\%) mentioned the presence of multimammate rats in/around the house as a risk factor for LF. Twenty-seven persons (27.7\%) reported the absence of rat-proof food storage containers as a risk factor for LF. The frequent clearing of bush/fumigation was stated as a measure to prevent the recurrence of LF among 58 (57.4\%) respondents. Among them, $2(2 \%)$ had a risk score of 0 , while $12(11.9 \%)$ had a risk score of 4 . Twenty-two $(21.8 \%)$ persons prevented the recurrence of LF by ensuring proper food storage and avoidance of out-of-home meals. The other risk factors for LF and measures to prevent its recurrence are shown in Table-2.

Among the respondents with primary education and below, 5 (29.4\%) were at higher risk for LF infection compared to $7(8.3 \%)$ with secondary education and above $(\mathrm{p}=0.014)$. Regarding ethnicity, $6(8 \%)$ of the Yoruba were at higher risk for LF compared to $6(23.1 \%)$ from other ethnic groups $(\mathrm{p}=0.041)$. In terms of sex, $5(8.1 \%)$ were at higher risk for LF compared to 7 females (17.1\%), although these differences are not statistically significant. The other associations

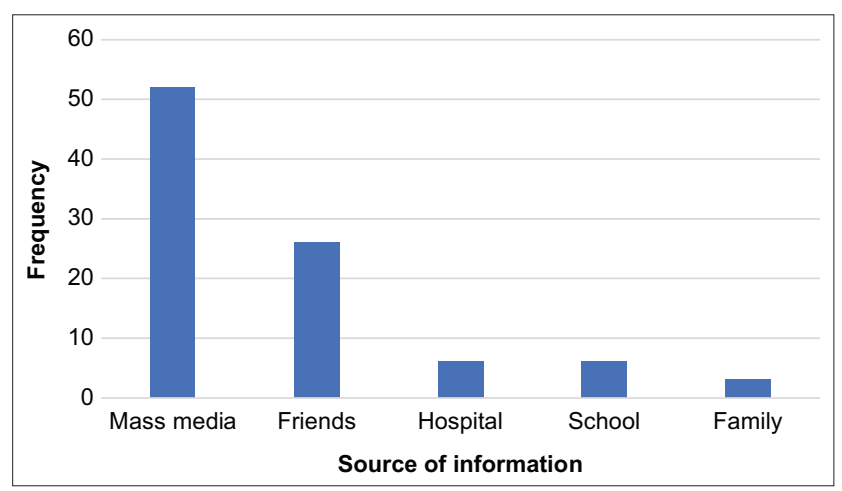

Figure-1: Sources of information on Lassa fever among respondents. 


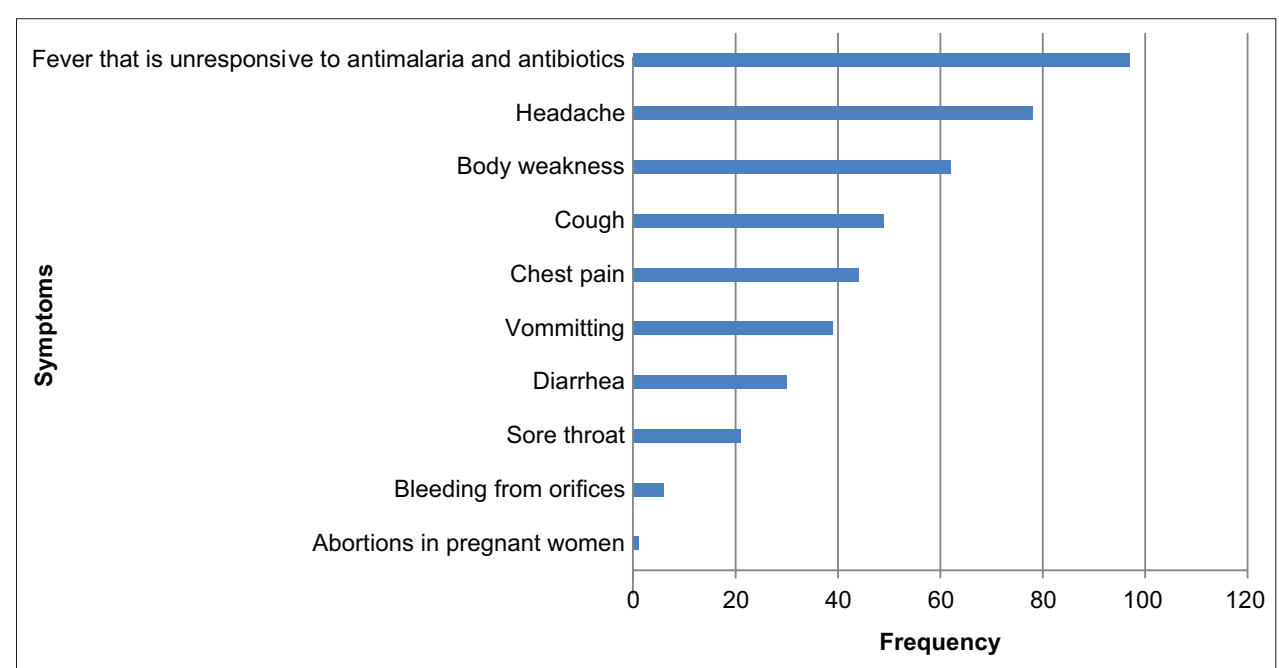

Figure-2: Symptoms of Lassa fever infection among respondents.

Table-2: Recognized risk factors of Lassa fever and measures to prevent recurrence among respondents.

\begin{tabular}{lcc}
\hline Risk factors & Frequency & \% \\
\hline $\begin{array}{l}\text { Presence of bush around the house } \\
\text { Presence of multimammate rats in/ }\end{array}$ & 63 & 62.4 \\
around the house & 28 & 58.4 \\
$\begin{array}{l}\text { Absence of rat proof containers for } \\
\text { food storage }\end{array}$ & 27.7 \\
$\begin{array}{l}\text { Recent contact with anyone who had } \\
\text { fever or died of unknown cause }\end{array}$ & 17 & 16.8 \\
Spreading of food items on the ground & 11 & 10.9 \\
Consumption of rats in the family & 2 & 2 \\
No identifiable risk factor & 2 & 2 \\
Risk scores & 2 & \\
0 & 26 & 25.7 \\
1 & 32 & 31.7 \\
2 & 29 & 28.7 \\
3 & 12 & 11.9 \\
4 & & \\
Measures put in place to prevent & & \\
recurrence & 58 & 57.4 \\
Frequent clearing of bush/fumigation & & 21.8 \\
Proper storage of food/avoidance of & 22 & \\
out-of-home meals & & \\
Regular hand washing & & \\
Change of residence/blocking of & 9 & 8.9 \\
crevices & & \\
\hline
\end{tabular}

between sociodemographic characteristics and risk categories are shown in Table-3.

\section{Discussion}

The results of this study revealed that the presence of bush and multimammate rats in/around the house is the potential factor increasing the risk for LF infection. The consumption of rats within the family was the only identified risk factor for LF in $2 \%$ of the respondents. This finding is unexpected because the residents of Ondo State are known for their rat hunting skills and love for rat meat consumption [14]. We found that only $2 \%$ with no identifiable risk got infected. This highlights that individuals are less likely to be infected in the absence of risk factors. This finding also indicates the possibility of infection in the absence of any identifiable risk. Hence, there is a need for all persons, either at high or low risk for LF, to always adopt infection prevention and control (IPC) measures.

Bush burning disrupts the ecosystem and displaces multimammate rats from their natural habitat. Therefore, these rats look for habitation elsewhere, and in the process, they may invade residential homes, increasing the chances of LF infection. To avoid this, mass campaigns should be organized to discourage bush burning in affected communities. During such campaigns, the community stakeholders could be actively involved to be educated about the risks involved in bush burning and related activities. Similarly, the consumption of other delicacies, such as goat meat, should be encouraged to reduce rat killing and maintain balance in the ecosystem.

Similarly, the absence of rat-proof containers for food storage was well-identified as a risk factor for LF infection. A significant association was found between food storage in rat-proof containers and the occurrence of LF [15]. When the containers are not covered with fitted lids, the rats can access the food items, placing the individuals at risk for LF infection [16]. Similarly, the studies conducted in Ebhodiza, Southwest Nigeria, point to the poor practice of rat prevention measures within home settings as a risk factor for LF infection [17]. A similar study conducted in Liberia corroborates the association between LF and poor waste disposal, accessibility of food preparation areas to rodents, and the absence of rodent-proof food storage containers [18].

The identification of recent contacts of persons who died of fever or unknown cause is consistent with the findings of a study where human-to-human transmission reinforced the known epidemiology of LF disease [16]. We also identified the spreading of food items on the ground as a risk factor for LF. This was corroborated by the International Fund for Agricultural Development, which stated that the roadside drying of food products could cause LF infection [19]. These findings point to the lifestyles, which could place one at risk for LF. 


\begin{tabular}{|c|c|c|c|c|}
\hline \multirow[t]{3}{*}{ Sociodemographic variable } & \multicolumn{2}{|c|}{ Risk category } & \multirow[t]{3}{*}{ Chi-square } & \multirow[t]{3}{*}{ p-value } \\
\hline & High & Low & & \\
\hline & n (\%) & n (\%) & & \\
\hline \multicolumn{5}{|l|}{ Age } \\
\hline$<25$ & $3(13.0)$ & $20(87.0)$ & 1.613 & 0.656 \\
\hline $25-39$ & $6(14.3)$ & $36(85.7)$ & & \\
\hline $40-59$ & $3(11.5)$ & $23(88.5)$ & & \\
\hline$\geq 60$ & $0(0.0)$ & $10(100.0)$ & & \\
\hline \multicolumn{5}{|l|}{ Sex } \\
\hline Male & $5(8.1)$ & 57 (91.9) & 2.234 & 0.135 \\
\hline Female & $7(17.9)$ & $32(82.1)$ & & \\
\hline \multicolumn{5}{|l|}{ Religion } \\
\hline Christianity & $10(11.9)$ & $74(88.1)$ & 0.000 & 0.987 \\
\hline Islam & $2(11.8)$ & $15(88.2)$ & & \\
\hline \multicolumn{5}{|l|}{ Highest level of education } \\
\hline Primary and below & $5(29.4)$ & $12(70.6)$ & 6.000 & 0.014 \\
\hline Secondary and above & $7(8.3)$ & $77(91.7)$ & & \\
\hline \multicolumn{5}{|l|}{ Ethnicity } \\
\hline Yoruba & $6(8.0)$ & $69(92.0)$ & 4.192 & 0.041 \\
\hline Others* & $6(23.1)$ & $20(76.9)$ & & \\
\hline \multicolumn{5}{|l|}{ Occupation } \\
\hline Artisan/ Trader & $6(14.3)$ & $36(85.7)$ & 2.518 & 0.472 \\
\hline Teacher/civil servant/health worker & $3(11.5)$ & $23(88.5)$ & & \\
\hline Student & $1(4.2)$ & $23(95.8)$ & & \\
\hline Unemployed/retirees & $2(22.2)$ & $7(77.8)$ & & \\
\hline \multicolumn{5}{|l|}{ Marital status } \\
\hline Single & $2(6.2)$ & $30(93.8)$ & 1.419 & 0.234 \\
\hline Married & $10(14.5)$ & $59(85.5)$ & & \\
\hline
\end{tabular}

*Igbo, Hausa, Urhobo, Igbira, and Igede

We found that the persons with primary education and below were at higher risk for LF. This finding contradicts the findings of a similar study conducted in Edo State, where about $90 \%$ of the respondents had a minimum of secondary school education [20]. Our study highlights that all persons, educated or not, are at risk for LF infection. The artisans and traders were noted to be at a higher risk for LF infection. The farmers in this category are involved in the production and sales of food items [21]. Hence, they could serve as transmitters of LF infections if precautionary measures are not followed. Precautionary measures, such as the preservation of farm products in tight-fitted equipment such as barns and silos, should be encouraged. Storage facilities should also be made readily available and accessible to farmers at subsidized costs by the federal government.

We identified mass media and friends as the main sources of LF information among the respondents. This is similar to otherstudies conducted in Edo and Oyo States [22,23]. It also agrees with the reports from Pulse, which stated that community information and mobilization for awareness generation are important for the control of rodents to avoid LF transmission [24]. Through awareness creation in community settings, community members identify rodent consumption as a risk factor for LF and are therefore able to adopt precautionary measures to avoid rodent consumption. This result highlights the critical role the active involvement of the mass media plays in communicating health-related information and prompting health-seeking behavior among individuals. These findings could have been due to the inclination of a larger population of the Ondo State toward the high usage of mass media. Thus, the active engagement of available mass media platforms in the communities should be done.

The high proportion of information provided by friends highlights the need for social networks and unit leaders in the community with LF-rich information. This study reveals that hospitals and schools are not the main sources of information about LF. Only a few respondents obtained the information about LF from the hospitals. This finding is contrary to the result in hospitals and schools conducted in the previous studies $[25,26]$. This could be due to the hospital-based setting in which this study was conducted. This finding is worrisome because hospitals and schools are known for enhanced communication of health information about non-LF illnesses [26,27]. Thus, the study implies the need for interventions, especially at health facilities, to engage all visiting persons for LF education sessions.

The results of this study reveal the symptoms of LF that the respondents presented with. The leading LF symptoms included fever that was unresponsive to medications, headache, and body weakness. These symptoms were similarly reported in a study conducted in Abakaliki, Nigeria, a LF endemic zone [25]. In addition, pregnancy loss was also reported as the 
least identified symptom in both studies. This highlights that similar presentations could accompany LF infection among different individuals.

Regarding the measures in place to prevent the recurrence of LF, the frequent clearing of bush and fumigation of the environment were well-reported among the respondents. An evidence from existing literature emphasized poor environmental sanitation as a major driver for LF outbreak [20]. In addition, proper food item storage and avoidance of out-ofhome meals should be done. The IPC measures were also reported as preventive measures against recurrent LF infections among the respondents. The need for these measures was also reported in a similar study conducted on health care workers [28]. The decision to change the residential apartments of respondents could be due to the proximity of the current residences to the dumping sites. Such proximity increases the possibility of LF outbreak [20]. Hence, the dumping sites should be located far from residential areas.

This study is limited to LF survivors on follow-up visits at the Federal Medical Center. The findings in this study could be different from other studies conducted in other LF endemic communities in Nigeria. In addition, the cross-sectional nature of this study could have limited our findings. Therefore, we suggest that longitudinal studies should be conducted among LF survivors.

\section{Conclusion}

The identification of the risk factors for LF is important in preventing LF transmission. A One Health approach is required to control its transmission. For the human component of the One Health approach, lifestyle modifications on hygienic practices and proper food storage should be encouraged. Storage equipment such as silos should be readily provided for farmers at subsidized or no costs. In addition, the mass media and other sources of information should be well-harnessed for the communication of risks and preventive practices for LF across all population groups. Health education should be intensified both in hospitals and schools to engage both young and old people in LF prevention activities. IPC measures need to be widely accepted and practiced at home and public settings to prevent further outbreaks of LF. For the environmental component of the One Health approach, public information campaigns should be organized to discourage bush burning in affected communities. During such campaigns, the community stakeholders could be actively involved to be educated about the risks involved in bush burning and related activities.

\section{Data availability}

The datasets used for the current study are available from the corresponding author on reasonable request.

\section{Authors' Contributions}

OSI, OTO, and AJA: Conceptualized and designed the study. OTO and AJA: Data collection. OSI and AAA: Data analysis. OSI, OTO, AJO, AAA, AOK, CA, and OOA: Review of data for critical intellectual content. All authors read and approved the final manuscript.

\section{Acknowledgments}

The authors are grateful to the patients who participated in the research. The authors did not receive any funds for this study.

\section{Competing Interests}

The authors declare that they have no competing interests.

\section{Publisher's Note}

Veterinary World (Publisher of International Journal of One Health) remains neutral with regard to jurisdictional claims in published institutional affiliation.

\section{References}

1. Ogbu, O., Ajuluchukwu, E. and Uneke, C.J. (2007) Lassa fever in West African sub-region: An overview. J. Vector. Borne Dis., 44(1): 1-11.

2. Atkin, S., Anaraki, S., Gothard, P., Walsh, A., Brown, D., Gopal, R., Hand, J. and Morgan, D. (2009) The first case of Lassa fever imported from Mali to the United Kingdom, February 2009. Euro. Surveill., 14(10): 1914.

3. Macher, A.M. and Wolfe, M.S. (2016) 2006: Historical Lassa fever reports and 30-year clinical update. Emerg. Infect. Dis., 12(5): 835-837.

4. Unit for Surveillance and Communication. (2008) E-alert: Case of Lassa fever imported into Germany from Sierra Leone. Euro. Surveill., 11(30): 3008.

5. Kitching, A., Addiman, S., Cathcart, S., Bishop, L., Krahé, D., Nicholas, M., Coakley, J., Lloyd, D., Brooks, T., Morgan, D. and Turbitt, D. (2009) A fatal case of Lassa fever in London. Euro. Surveill., 14(6): 19117.

6. Amorosa, V., MacNeil, A., McConnell, R., Patel, A., Dillon, K.E., Hamilton, K., Erickson, B.R., Campbell, S., Knust, B., Cannon, D., Miller, D., Manning, C., Rollin, P.E. and Nichol, S.T. (2010) Imported Lassa fever, Pennsylvania, USA. Emerg. Infect. Dis., 16(10): 1598-600.

7. Ilesanmi, O.S. and Alele, F.O. (2015) Awareness of Lassa fever in a rural community in South West Nigeria. $J$. Community Health Res., 4(1): 1-10.

8. McCormick, J. (1999) Lassa fever. In: Saluzzo, J.F. and Dodet, B., editors. Emergence and Control of Rodent-borne Viral Diseases. Elsevier, Netherlands. p177-195.

9. Frame, J.D., Baldwin, J.M.J., Gocke, D.J. and Troup, J.M. (1970) Lassa fever, a new virus disease of man from West Africa: Clinical description and pathological findings. $\mathrm{Am}$. J. Trop. Med. Hyg., 19(4): 670-676.

10. Nigeria Centre for Disease Control. (2020) Lassa fever situation report. Epi Week 29:13-19. Available from: https:// www.ncdc.gov.ng/diseases/sitreps $/$ ?cat $=5 \%$ name $=\mathrm{An} \% 20$ update $\% 20$ of $\% 20$ Lassa $\% 20$ fever $\% 20$ outbreak $\% 20 \mathrm{in} \% 20$ NigeriaU3. Retrieved on 04-08-2020.

11. Ter Meulen, J., Lukashevich, I., Sidibe, K., Inapogui, A., Marx, M., Dorlemann, A., Yansane, M.L., Koulemou, K., Claude-Chang, J. and Schmitz, H. (1996) Hunting of peridomestic rodents and consumption of their meat as possible risk factors for rodent-to-human transmission of Lassa virus in the Republic of Guinea. Am. J. Trop. Med. Hyg., 55(6): 
661-666.

12. Healing, T. and Gopal, R. (2001) Report on an Assessment Visit to Sierra Leone. Merlin, London.

13. Awosanya, E.J. (2018) Post-epidemic awareness and knowledge of Lassa fever among residents in affected communities in Ibadan, Oyo State, Nigeria. Vet. World., 11(8): 1059-1063.

14. Agency Report. (2020) Lassa Fever: Ondo Launches Operation Kill all Rats, Live in Hygienic Environment. Available from: https://www.premiumtimesng.com/ regional/ssouth-west/240488-lassa-fever-ondo-launches-operation-kill-rats-live-hygienic-environment.html. Retrieved on 20-07-2020.

15. Asogun, D., Okokhere, P., Tobin, E., Okogbenin, S.A., Akpede, G., Happi, C. and Gunther, S. (2012) Lassa fever practice challenges in Nigeria. Int. J. Infect. Dis., 16(1): e69.

16. Saka, J.M., Bintu Gubio, A., Kerecvel, Y.S., Saka, A.O. and Oyemakinde, A. (2017) Lassa fever epidemic in Nigeriaoutbreak investigation, risk factors and empirical analysis from 2012 to 2016. J. Community Public Health Nurs., 3(2): $1-6$.

17. Asogun, D., Okokhere, P., Okogbenin, S., Akpede, G., Gunther, S. and Happi, C. (2010) Lassa fever awareness and practices in a Nigerian rural community. Int. J. Infect. Dis., 14(1): e208.

18. Hamblion, E.L., Ratfery, P., Wendland, A., Dweh, E., Williams, G.S., George, L.N.C., Soro, L., Katawera, V., Clement, P., Gasasira, A.N., Musa, E. and Nagbe, T.K. (2018) The challenges of detecting and responding to a Lassa fever outbreak in an Ebola-affected setting. Int. $J$. Infect. Dis., 66: 65-73.

19. Asishana, J. (2020) Road Side Drying of Food Can Cause Lassa Fever, Appendicitis-IFAD Warns. Available from: https://www.thenationonlineng.net/roadside-drying-offood-produce-can-cause-lassa-fever-appendicitis-ifadwarns. Retrieved on 20-07-2020.

20. Ekechi, H.U., Ibeneme, C., Ogunniyi, B., Awosanya, E., Gbadebo, B., Usman, A., Balogun, M.S., Ameh, C., Okeke, L., Dan-Nwafor, C. and Ihekweazu, C. (2020)
Factors associated with a confirmed Lassa fever outbreak in Eguare community of Esan West, Edo State, Nigeria: January-March, 2019. J. Interval Epidemiol. Public Health, 3(1): 1-12.

21. People's Agenda 21. (2020) The Role of Farmers and Food Production Systems. Available from: https://www.peoplesagenda21.com/the-role-of-farmers-and-food-production-systems. Retrieved on 20-07-2020.

22. Aigbiremolen, A., Chukwuma, B.D., Nyemike, S.A., Abah, S.O., Asogun, A.D. and Eguavoen, O. (2012) Knowledge and application of infectious diseases control measures among Primary Care workers in Nigeria: The Lassa fever example. IJBAIR, 1(4): 122-129.

23. Tobin, E.A., Asogun, D., Akpede, N., Adomeh, D., Odia, I. and Gunther, S. (2015) Lassa fever in Nigeria: Insights into seroprevalence and risk factors in rural Edo State: A pilot study. J. Med. Trop., 17(2): 51-55.

24. Pulse Nigeria. (2020) Physician Advocates War Against Rats. Available from: https://www.pulse.ng/news/local/ lassa-fever-physician-advocates-war-against-rats/xy3z8d1. Retrieved on 20-07-2020.

25. Usuwa, S.I., Akpa, C.O., Umeokonkwo, C.D., Umoke, M., Oguanuo, C.S., Olorukooba, A.A., Bamgboye, E. and Balogun, M.S. (2020) Knowledge and risk perception towards Lassa fever infection among residents of affected communities in Ebonyi State, Nigeria: Implications for risk communication. BMC Public Health, 20(1): 217.

26. Markos, M. (2011) The importance of good communication between patient and health professionals. J. Pediatr. Hematol. Oncol., 33(1): S123-S125.

27. World Health Organization. (2020) Global Strategy on Diet, Physical Activity, and Health (n.d.). The Role of Schools. Available from: https://www.who.int/dietphysicalactivity/ childhood_schools/en. Retrieved on 20-07-2020.

28. Ijarotimi, I.T., Ilesanmi, O.S., Aderinwale, A., AbiodunAdewusi, O. and Okon, I.M. (2018) Knowledge of Lassa fever and use of infection prevention and control facilities among health care workers during Lassa fever outbreak in Ondo State, Nigeria. Pan. Afr. Med. J., 30: 56.

\section{$* * * * * * * *$}

